\title{
Pulmonary immuno-thrombosis in COVID-19 ARDS pathogenesis
}

\author{
James S. O'Donnell ${ }^{1,2,3^{*}}$ (D) Flora Peyvandi ${ }^{4,5}$ and Ignacio Martin-Loeches ${ }^{1,6,7}$
}

() 2021 The Author(s)

Severe acute respiratory syndrome coronavirus 2 (SARSCoV-2) is responsible for coronavirus disease 2019 (COVID-19). Recent data highlight a pivotal role for pulmonary immuno-thrombosis in COVID-19 in the pathogenesis of severe COVID-19.

SARS-CoV-2 gains entry into airway epithelial cells via ACE2 receptors, and subsequently triggers infiltration of monocytes, macrophages, and $\mathrm{T}$ cells into the alveoli [1]. This is accompanied by local cytokine and chemokine generation, leading to elevated systemic levels of cytokines including TNF- $a$, IL-1 $\beta$, IL- 6 , and IL-8 [1]. In addition to the local pulmonary inflammatory response, hemostatic dysfunction has also been implicated in COVID-19 pathogenesis [2, 3]. Moreover, elevated fibrin degradation D-dimer levels constitute an independent biomarker for poor clinical outcomes [3]. Post-mortem studies in COVID-19 have consistently reported the presence of thrombi in both the micro- and macro-vasculature of the lungs [4-7]. Composed predominantly of platelets and fibrin, these thrombi have been identified in precapillary arteries, alveolar capillaries, as well as postcapillary venules [4-7]. Ackerman et al. estimated that alveolar capillary microthrombi were nine times more common in COVID-19 patients compared to those with severe influenza [4]. Pulmonary thrombi in COVID-19 were hetero-synchronous in nature, displaying different stages of organization [7]. This observation suggests that they have developed in situ rather than being embolic in origin [5]. Interestingly, megakaryocytes were observed in association with microvascular thrombi

\footnotetext{
*Correspondence: jamesodonnell@rcsi.ie

${ }^{1}$ Irish Centre for Vascular Biology, School of Pharmacy and Biomolecular Sciences, Royal College of Surgeons in Ireland, Ardilaun House, 111 St. Stephen's Green, Dublin 2, Ireland

Full author information is available at the end of the article
}

within alveolar capillaries and ongoing platelet production could be seen $[5,6]$. Given the platelet-rich nature of the microthrombi, these data suggest that platelet activation is important in the development of COVID-19 pulmonary microangiopathy. Pulmonary microthrombi also contained trapped partly degenerated neutrophils consistent with NETosis [6]. Importantly, intra-alveolar fibrin deposition was also observed post-mortem and hypothesized to contribute to the increased D-dimer levels [6]. Collectively, patients with severe COVID-19, therefore, have concurrent pathologies targeting ventilation $(\mathrm{V})$ and perfusion $(\mathrm{Q})$ within the lungs, which likely explains their severe hypoxia and the refractory nature of their acute respiratory distress syndrome (ARDS).

Although dysregulated inflammatory responses and hemostatic dysfunction have both been implicated in COVID-19 pathogenesis, it is important to appreciate that these two processes do not function as discrete entities. Rather, a dynamic cross-talk exists between inflammation and hemostasis pathways in vivo. For example, pro-inflammatory cytokines including TNF- $\alpha$ and IL-1 $\beta$ both trigger upregulation of tissue factor (TF) expression on endothelial cells (EC) and monocytes, a major initiator of in vivo coagulation. Conversely, activated coagulation enzymes such as thrombin can initiate pro-inflammatory signaling cascades through proteolytic cleavage of cell surface protease-activated receptors (PARs). This bidirectional cross-talk between haemostasis and inflammation has been comprehensively reviewed $[8,9]$.

Emerging findings suggest that pulmonary immunothrombosis plays a critical role in COVID-19 pathogenesis (Fig. 1). In normal blood vessels, the EC monolayer lining the vascular wall functions to prevent the development of pathological thrombosis. SARS-CoV-2 infection has specific deleterious effects upon pulmonary EC (Fig. 1) [10]. Post-mortem studies have highlighted EC swelling, disruption of EC intercellular junctions, loss

\section{Springer}


of EC contact with the basement membrane and significant EC apoptosis [4-7]. SARS-CoV-2 endotheliopathy is likely multifactorial in etiology, with damage mediated by pro-inflammatory cytokines, complement activation, as well as other mechanisms including severe hypoxia. Interestingly, ACE-2 receptor is also expressed on EC and electron microscopy studies have observed viral particles within pulmonary EC [4]. Irrespective of the underlying mechanisms, EC activation causes secretion of high molecular weight von Willebrand factor (HMW-VWF) multimers from Weibel Palade bodies (WPB) (Fig. 1). Consequently, plasma VWF:Ag and VWF propeptide levels are markedly elevated approximately eight-tenfold in patients with severe COVID-19 [11, 12]. Secreted VWF becomes tethered on the EC surface to form elongated
VWF strings, which can then recruit platelets, neutrophils, and monocytes to the blood vessel wall (Fig. 1). EC activation also causes externalization of P-selectin from WPB stores to the EC surface where it facilitates leukocyte adherence. In addition, post-mortem studies in COVID-19 have reported upregulated EC expression of other adhesion molecules, including VCAM-1, ICAM1 , and E-selectin, which further promote recruitment of neutrophils and monocytes (Fig. 1) [7]. These cells exacerbate EC damage through a variety of mechanisms including local pro-inflammatory cytokine, production of NETs and release of reactive oxygen species (ROS). Importantly, the pro-inflammatory milieu also results in TF expression and decryption on both EC and monocytes (Fig. 1). This TF interacts with circulating FVIIa

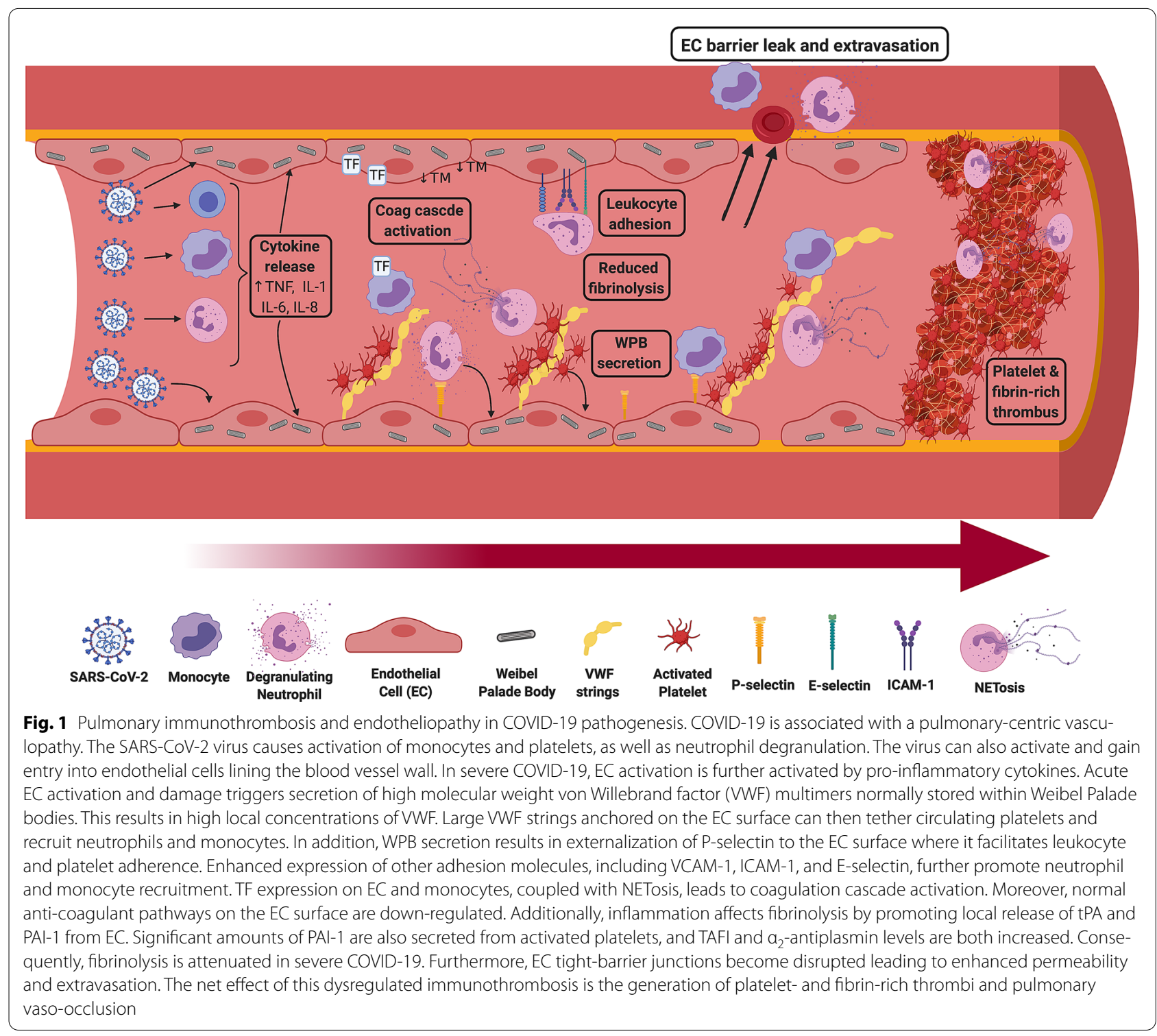


to trigger extrinsic pathway coagulation activation and thrombin generation. Inflammatory pathways simultaneously inhibit normal anti-coagulant and pro-fibrinolytic properties of EC surfaces. For example, severe COVID-19 is associated with enhanced shedding of thrombomodulin (TM) from EC surfaces which attenuates generation of anticoagulant activated protein C (APC) (Fig. 1) [12].

In addition to this endotheliopathy, studies have shown that severe COVID-19 is associated with multifactorial platelet activation (Fig. 1). Important causes of platelet activation include pro-inflammatory cytokines, thrombin generation, immune complexes, anti-PF4 antibodies, hypoxia, and NETosis. Following activation, platelets express $\mathrm{P}$-selectin and $\mathrm{CD} 40 \mathrm{~L}$ and consequently can interact with neutrophils to enhance cytokine release. Activation also causes secretion of platelet $\alpha$-granule contents including VWF, as well as a range of pro-inflammatory cytokines and chemokines. Finally, pulmonary immunothrombosis causes enhanced vascular permeability, which serves to facilitate leucocyte extravasation and exacerbates alveolar inflammation and edema (Fig. 1). Together, the net effect of this combined local endotheliopathy and thrombocytopathy is ultimately the generation of platelet-fibrin rich thrombi disseminated throughout the pulmonary vasculature.

Given the complex multifactorial mechanisms involved in SARS-CoV-2 pulmonary immunothrombosis, it seems unlikely that a one-size-fits-all approach to treatment will be sufficient [13]. Recent data suggest that anticoagulation has an important role to play [14]. However, important questions remain regarding optimal dosage and how this may need to be altered at different stages during the patient's COVID-19 journey. In particular, increased bleeding has been reported with therapeutic heparin in severe COVID-19 [14]. Alternative treatment strategies targeted at reducing COVID-19 endotheliopathy (e.g. defibrotide, statins and prostacyclin) and complement inhibition are also being evaluated [13]. In view of the evidence of the marked WPB exocytosis seen in acute COVID-19, reducing VWF activity (e.g. recombinant ADAMTS13 or caplacizumab) or inhibiting P-selectin interaction with leucocytes and platelets (e.g. crizanlizumab), may also be useful [15]. Since thrombocytopathy plays a key role in COVID-19 pulmonary immunothrombosis, ongoing studies are investigating the role of various ant-platelet therapies (e.g. aspirin, dipyridamole or P2Y12 inhibitors). Finally, since immunothrombosis is the primary driver of the pathogenesis, different forms of immunomodulatory treatment are also being studied (e.g. dexamethasone, tocilizumab or canakinumab). Further insights into the basic science underlying SARSCoV-2 pathobiology will be essential so that patients can be accurately stratified into subgroups that should ultimately determine their optimal treatment regimen combination.

\section{Author details \\ ${ }^{1}$ Irish Centre for Vascular Biology, School of Pharmacy and Biomolecular Sci- ences, Royal College of Surgeons in Ireland, Ardilaun House, 111 St. Stephen's Green, Dublin 2, Ireland. ${ }^{2}$ National Coagulation Centre, St James's Hospital, Dublin, Ireland. ${ }^{3}$ National Children's Research Centre, Our Lady's Children's Hospital Crumlin, Dublin, Ireland. ' Fondazione IRCCS Ca' Granda-Ospedale Maggiore Policlinico Angelo Bianchi Bonomi Hemophilia and Thrombosis Center, Via Pace 9, 20122 Milan, Italy. ${ }^{5}$ Department of Pathophysiology and Transplantation, Università degli Studi di Milano, Milan, Italy. ${ }^{6}$ St James's Hospital, Trinity College Dublin, Dublin, Ireland. ${ }^{7}$ Hospital Clinic, IDIBAPS, Universidad de Barcelona, CIBERES, Barcelona, Spain.}

\section{Acknowledgements \\ JOS'D and the Irish COVID-19 vasculopathy study (ICVS) are supported by a Health Research Board COVID-19 Rapid Response award (COV19-2020-086); a philanthropic grant from the 3M Foundation to RCSI University of Medicine and Health Sciences in support of COVID-19 research; and the National Children's Research Centre Project Award (C/18/1). FP is partially supported by the Italian Ministry of Health-Bando Ricerca Corrente and partially financed by Italian fiscal contribution "5x1000" 2017 devolved to Fondazione IRCCS Ca' Granda Ospedale Maggiore Policlinico. IML is supported by a Science Founda- tion Ireland, Enterprise Ireland, IDA Ireland COVID-19 Rapid Response award (20/COV/0038).}

\section{Author contributions}

All authors contributed to final draft writing and critical revision.

Funding

Open Access funding provided by the IReL Consortium.

\section{Declarations}

\section{Conflicts of interest}

JSO'D has served on the speaker's bureau for Baxter, Bayer, Novo Nordisk, Sobi, Boehringer Ingelheim, Leo Pharma, Takeda, and Octapharma. He has also served on the advisory boards of Baxter, Sobi, Bayer, Octapharma CSL Behring, Daiichi Sankyo, Boehringer Ingelheim, Takeda, and Pfizer. He has also received research grant funding awards from 3 M, Baxter, Bayer, Pfizer, Shire, Takeda, $3 \mathrm{M}$ and Novo Nordisk. FP received honoraria for participating as a speaker at educational meetings, symposia and advisory boards of Roche-SobiSanofi-Grifols - Takeda.

\section{Open Access}

This article is licensed under a Creative Commons Attribution-NonCommercial 4.0 International License, which permits any non-commercial use, sharing, adaptation, distribution and reproduction in any medium or format, as long as you give appropriate credit to the original author(s) and the source, provide a link to the Creative Commons licence, and indicate if changes were made. The images or other third party material in this article are included in the article's Creative Commons licence, unless indicated otherwise in a credit line to the material. If material is not included in the article's Creative Commons licence and your intended use is not permitted by statutory regulation or exceeds the permitted use, you will need to obtain permission directly from the copyright holder. To view a copy of this licence, visit http://creativecommons.org/licen ses/by-nc/4.0/.

\section{Publisher's Note}

Springer Nature remains neutral with regard to jurisdictional claims in published maps and institutional affiliations.

Received: 19 February 2021 Accepted: 21 April 2021

Published online: 30 May 2021 


\section{References}

1. McGonagle D, O'Donnell JS, Sharif K, Emery P, Bridgewood C (2020) Immune mechanisms of pulmonary intravascular coagulopathy in COVID-19 pneumonia. Lancet Rheumatol 2:e437-e445

2. Panigada M, Bottino N, Tagliabue P, Grasselli G, Novembrino C, Chantarangkul V, Pesenti A, Peyvandi F, Tripodi A (2020) Hypercoagulability of COVID-19 patients in intensive care unit: a report of thromboelastography findings and other parameters of hemostasis. J Thromb Haemost 18:1738-1742

3. Tang N, Li D, Wang X, Sun Z (2020) Abnormal coagulation parameters are associated with poor prognosis in patients with novel coronavirus pneumonia. J Thromb Haemost 18:844-847

4. Ackermann M, Verleden SE, Kuehnel M, Haverich A, Welte T, Laenger F, Vanstapel A, Werlein C, Stark H, Tzankov A, Li WW, Li VW, Mentzer SJ, Jonigk D (2020) Pulmonary vascular endothelialitis, thrombosis, and angiogenesis in covid-19. N Engl J Med 383:120-128

5. Rapkiewicz AV, Mai X, Carsons SE, Pittaluga S, Kleiner DE, Berger JS, Thomas S, Adler NM, Charytan DM, Gasmi B, Hochman JS, Reynolds HR (2020) Megakaryocytes and platelet-fibrin thrombi characterize multiorgan thrombosis at autopsy in COVID-19: A case series. EClinicalMedicine 24:100434

6. Fox SE, Akmatbekov A, Harbert JL, Li G, Quincy Brown J, Vander Heide RS (2020) Pulmonary and cardiac pathology in African American patients with COVID-19: an autopsy series from New Orleans. Lancet Respir Med 8:681-686

7. Bussani R, Schneider E, Zentilin L, Collesi C, Ali H, Braga L, Volpe MC, Colliva A, Zanconati F, Berlot G, Silvestri F, Zacchigna S, Giacca M (2020) Persistence of viral RNA, pneumocyte syncytia and thrombosis are hallmarks of advanced COVID-19 pathology. EBioMedicine 61:103104
8. Foley JH, Conway EM (2016) Cross talk pathways between coagulation and inflammation. Circ Res 118:1392-1408

9. Engelmann B, Massberg S (2013) Thrombosis as an intravascular effector of innate immunity. Nat Rev Immunol 13:34-45

10. O'Sullivan JM, Gonagle DM, Ward SE, Preston RJS, O'Donnell JS (2020) Endothelial cells orchestrate COVID-19 coagulopathy. Lancet Haematol 7:e553-e555

11. Ward SE, Curley GF, Lavin M, Fogarty H, Karampini E, McEvoy NL, Clarke J, Boylan M, Alalqam R, Worrall AP, Kelly C, de Barra E, Glavey S, Ni Cheallaigh C, Bergin C, Martin-Loeches I, Townsend L, Mallon PW, O'Sullivan JM, O'Donnell JS, Irish C-VSI (2021) Von Willebrand factor propeptide in severe coronavirus disease 2019 (COVID-19): evidence of acute and sustained endothelial cell activation. Br J Haematol 192(4):714-719

12. Goshua G, Pine AB, Meizlish ML, Chang CH, Zhang H, Bahel P, Baluha A, Bar N, Bona RD, Burns AJ, Dela Cruz CS, Dumont A, Halene S, Hwa J, Koff J, Menninger H, Neparidze N, Price C, Siner JM, Tormey C, Rinder HM, Chun HJ, Lee Al (2020) Endotheliopathy in COVID-19-associated coagulopathy: evidence from a single-centre, cross-sectional study. Lancet Haematol 7:e575-e582

13. Gu SX, Tyagi T, Jain K, Gu VW, Lee SH, Hwa JM, Kwan JM, Krause DS, Lee Al, Halene S, Martin KA, Chun HJ, Hwa J (2021) Thrombocytopathy and endotheliopathy: crucial contributors to COVID-19 thromboinflammation. Nat Rev Cardiol 18:194-209

14. Hunt BJ, De Paula EV, MCLintock C, Dumantepe M (2021) Prophylactic anticoagulation for patients in hospital with covid-19. BMJ 372:n487

15. Lowenstein CJ, Solomon SD (2020) Severe COVID-19 is a microvascular disease. Circulation 142:1609-1611 